\title{
COMMISSIONING OF THE LINAC FOR THE HEIDELBERG HEAVY ION CANCER THERAPY CENTRE (HIT)
}

\author{
M. Maier, W. Barth, W. Bayer, L. Dahl, L. Groening, C. Kleffner, B. Schlitt, K. Tinschert, \\ H. Vormann, S. Yaramyshev, GSI, Darmstadt, Germany \\ U. Ratzinger, A. Schempp, IAP, University of Frankfurt am Main, Germany
}

\section{Abstract}

A clinical accelerator facility for cancer therapy using energetic proton and ion beams $(\mathrm{C}, \mathrm{He}$ and $\mathrm{O})$ is currently under commissioning at the Radiologische Universitätsklinik in Heidelberg, Germany. It consists of two ECR ion sources, a $7 \mathrm{MeV} / \mathrm{u}$ linac injector, and a $6.5 \mathrm{Tm}$ synchrotron to accelerate the ions to final energies of $50-$ $430 \mathrm{MeV} / \mathrm{u}$. The linac comprises a $400 \mathrm{keV} / \mathrm{u}$ RFQ and a $7 \mathrm{MeV} / \mathrm{u}$ IH-DTL operating at $216.8 \mathrm{MHz}$. The commissioning of the linac was performed in three steps for the LEBT, the RFQ, and the IH-DTL. For this purpose a dedicated beam diagnostics test bench was used. In this contribution the procedures and the results of the successful beam commissioning of the linear accelerator in the year 2006 are reported.

\section{INTRODUCTION}

The accelerator chain of the heavy ion cancer therapy centre (HIT) [1] at the Radiologische Universitätsklinik in Heidelberg, Germany consists of two ECR ion sources, a $7 \mathrm{MeV} / \mathrm{u}$ linac injector and a $6.5 \mathrm{Tm}$ synchrotron to accelerate the ions to final energies of $50-430 \mathrm{MeV} / \mathrm{u}$.

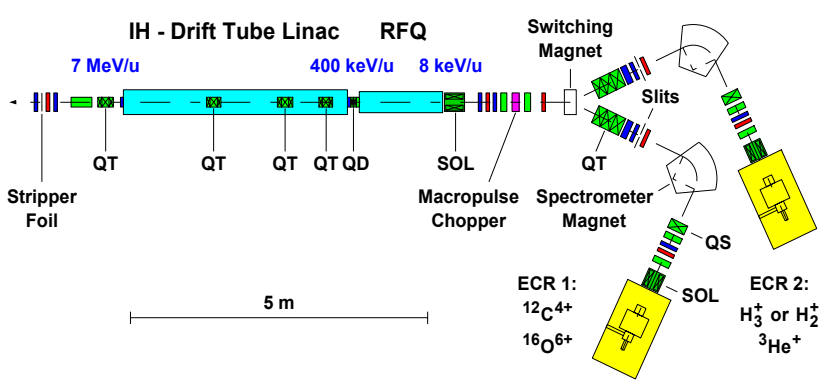

Figure 1: Layout of the HIT injector linac [2]. QS, QD, and QT means quadrupole-singulet, -doublet and -triplet, respectively, SOL means solenoid magnet; focusing and steering magnets (green), profile grids and tantalum screen (red), and beam current monitors (blue).

Table 1: Main design parameters at the HIT linac exit

\begin{tabular}{|c|c|}
\hline Design ion & ${ }^{12} \mathrm{C}^{4+}$ \\
\hline Operating frequency & $216.816 \mathrm{MHz}$ \\
\hline Final beam energy & $7 \mathrm{MeV} / \mathrm{u}$ \\
\hline Beam pulse length & $300 \mu \mathrm{s}$ \\
\hline Beam repetition rate & $5 \mathrm{~Hz}$ \\
\hline Pulse current after stripping & $100 \mathrm{e} \mu \mathrm{A}\left({ }^{12} \mathrm{C}^{6+}\right)$ \\
\hline Transverse emittances $(95 \%)$ & $0.8 \mu \mathrm{m}$ (norm.) \\
\hline Exit energy spread $^{1}$ & $\pm 0.3 \%$ \\
\hline Total linac length $^{2}$ & $\approx 13 \mathrm{~m}$ \\
\hline
\end{tabular}

Table 2: Milestones of the HIT linac commissioning

\begin{tabular}{|l|l|l|}
\hline Nov. 05-Mar 06 & $\begin{array}{l}\text { ECRIS, } \\
\text { LEBT }\end{array}$ & $\begin{array}{l}\text { installation, testing of } \\
\text { components }\end{array}$ \\
\hline April - May 06 & ECRIS & $\begin{array}{l}\text { successful beam } \\
\text { commissioning }\end{array}$ \\
\hline May - July 06 & LEBT & $\begin{array}{l}\text { installation, } \\
\text { rf commissioning }\end{array}$ \\
July - August 06 & \multirow{2}{*}{ RFQ } & $\begin{array}{l}\text { beam acceleration } \\
\text { to 400 keV/u }\end{array}$ \\
\cline { 1 - 1 } September 06 & \multirow{2}{*}{ IH-DTL } & installation \\
\cline { 3 - 3 } October 06 & $\begin{array}{l}\text { rf commissioning } \\
\text { beam acceleration to } \\
7 \mathrm{MeV} / \mathrm{u}\end{array}$ \\
\hline November 06 & \multirow{2}{*}{ Lecember 06 } & $\begin{array}{l}50^{6 \%} \text { performance, } \\
\mathrm{C}^{6+} \text { injection into } \\
\text { synchrotron }\end{array}$ \\
\hline February 2007 & &
\end{tabular}

The injector linac [2] shown in Fig. 1 comprises the low energy beam transfer lines (LEBT), a $400 \mathrm{keV} / \mathrm{u}$ Radio Frequency Quadrupole (RFQ) accelerator [3], and a $7 \mathrm{MeV} / \mathrm{u}$ IH-type Drift Tube Linac (IH-DTL) operating at $216.8 \mathrm{MHz}$ [2][4]. Table 1 gives the design parameters for carbon beams. The commissioning of the linac injector was performed in three consecutive steps for the LEBT, the RFQ, and the IH-DTL as listed in Table 2.

\section{MOBILE TEST BENCH}

In order to measure the beam performances behind the different linac sections a mobile beam diagnostics test bench was used. After installation of each section, this diagnostics bench was placed at the very end of this section. The bench comprised all instrumentation needed
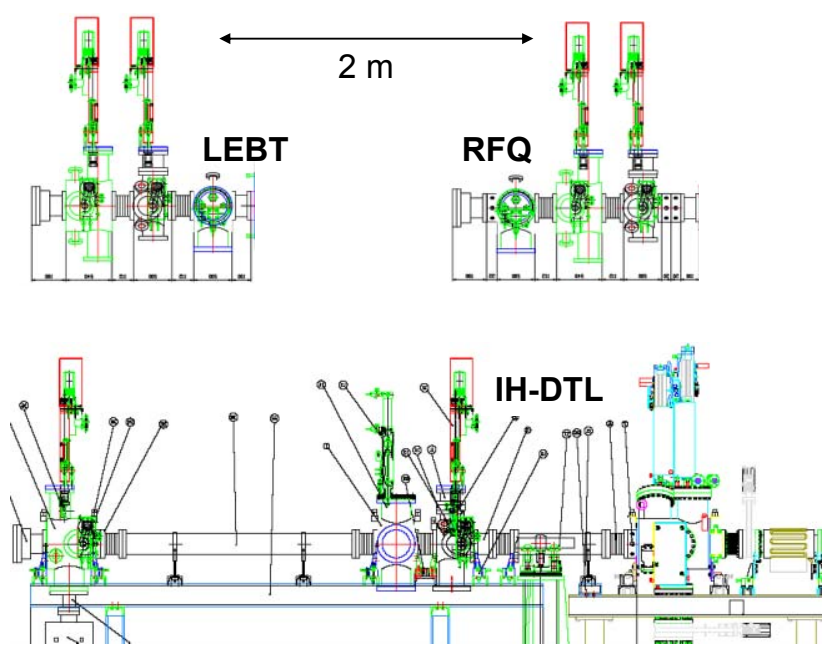

Figure 2: Mobile beam diagnostics benches used during beam commissioning of the different linac sections. The beam enters from the right, respectively. 
to measure the relevant beam characteristics, i.e. a beam current transformer, a horizontal and vertical slit-grid emittance measurement device, and a Faraday end-cup. After the commissioning of a section finished the next linac section was installed, and the set-up was reinstalled behind the next section to be commissioned.

For the commissioning of the RFQ and of the IH-DTL three phase probes were included to measure the beam energy via the time-of-flight (TOF) technique. To preserve the measurement resolutions at higher beam energy, the IH-DTL set-up was extended with respect to the RFQ set-up. The different set-ups of the bench are shown in Fig. 2.

\section{LEBT}

The two-branch LEBT (Fig. 3) comprises a solenoid magnet directly behind each ion source, a single quadrupole lense to match into the $90^{\circ}$ analyzing dipole followed by a quadrupole triplet, a switching magnet, and a solenoid in front of the RFQ.

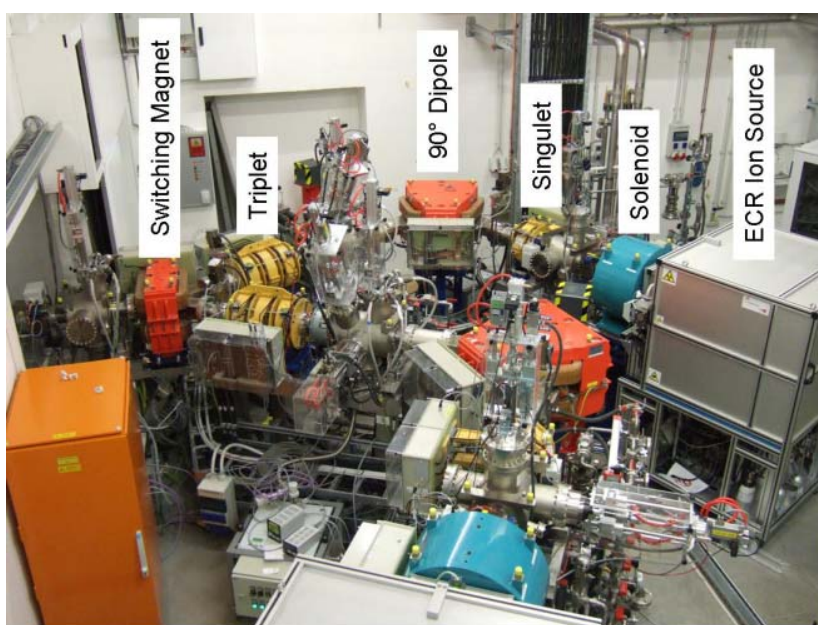

Figure 3: The two LEBT branches of the HIT linac.

Table 3: Ion species, specified as well as measured beam intensities behind the analyzing dipoles

\begin{tabular}{|c|c|c|c|}
\hline Ion & $\mathrm{I} / \mu \mathrm{A}$ (spec.) & $\mathrm{I} / \mu \mathrm{A}$ (meas.) & $\mathrm{U}_{\text {source }} / \mathrm{kV}$ \\
\hline${ }^{1} \mathrm{H}_{3}{ }^{+}$ & 700 & $\approx 710$ & 24 \\
\hline${ }^{3} \mathrm{He}^{1+}$ & 500 & $\approx 840$ & 24 \\
\hline${ }^{12} \mathrm{C}^{4+}$ & 200 & $\approx 200$ & 24 \\
\hline${ }^{16} \mathrm{O}^{6+}$ & 150 & $\approx 170$ & 21.3 \\
\hline
\end{tabular}

The goal of the LEBT commissioning was to provide the matched-beam settings for the ion species listed in Table 3. After the spectrum analyzing bend the ion beams could be transported to the end of the LEBT with a transmission of $\geq 90 \%$. A strong influence of the field strength of the solenoid for matched injection into the RFQ on beam steering and emittance was observed. An off-line field mapping revealed a strong transverse field bump with a relative strength up to $1.3 \%$ with respect to the main solenoid field. At the LEBT exit normalized transverse emittances up to $1.2 \mu \mathrm{m}$ were measured. The design value is $0.75 \mu \mathrm{m}$. A detailed report on the LEBT commissioning is given in Ref. [5].

\section{RFQ}

The RFQ cavity was delivered to GSI in March 2005. Rf-testing with an rf power up to $200 \mathrm{~kW}$ was performed successfully at GSI as well as the final low-level tuning of the field flatness. Prior to the commissioning in Heidelberg an RFQ beam test bench using proton beams had been set up at GSI [6] in order to verify the output beam energy by TOF measurements and to check the correct function of the two-gap rebuncher drift tube set-up integrated into the RFQ tank. The test bench also allowed for testing of the final rf amplifier, the control system, and the beam diagnostics components.

After shipping the RFQ first $\mathrm{C}^{4+}$ beams at $400 \mathrm{keV} / \mathrm{u}$ were observed on site in September 2006. Right after the RFQ a pair of steerers and a quadrupole doublet provide for transverse matching into the IH-DTL. The mobile diagnostics bench was directly installed behind the doublet during RFQ commissioning.

The RFQ working point was determined by measuring the beam energy and transmission as functions of the applied rf input power. Fig. 4 shows the measured beam energy at the RFQ exit as function of the applied tank voltage. The working point is defined by achieving the design output energy. An rf pulse power of $190-200 \mathrm{~kW}$ is needed for ${ }^{12} \mathrm{C}^{4+}$ operation.

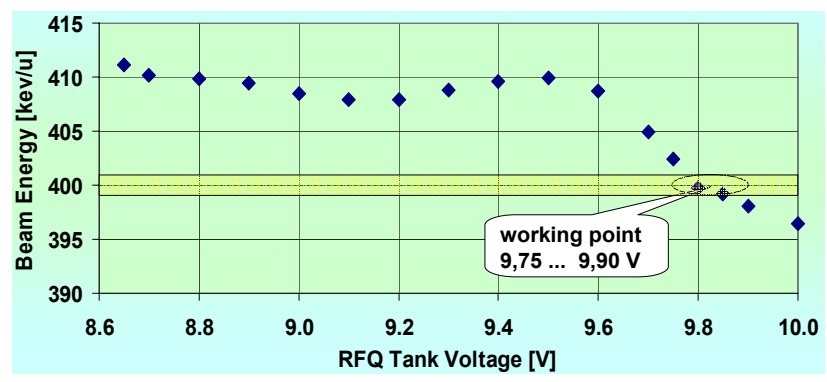

Figure 4: Measured RFQ output energy as function of the (scaled) tank voltage for ${ }^{12} \mathrm{C}^{4+}$ operation.

A strong dependence of the steering on the rf voltage was observed. Accordingly, the steerers at the RFQ exit had to be set for each tank voltage individually. Significant misalignment of the RFQ electrodes was partly corrected during RFQ commissioning.

\section{IH-DTL}

The $3.8 \mathrm{~m}$ long IH-cavity (Fig. 5) includes three internal quadrupole triplets and applies the KONUS beam dynamics scheme [7]. It was delivered to GSI in summer 2005 followed by copper plating, final drift tube assembly, and vacuum testing. After rf tuning especially with respect to field flatness [8] the cavity was installed on site in October 2006.

The working point of the IH cavity is given by the rf input power and -phase with respect to the preceding RFQ. Fig. 6 shows the measured linac beam energy as function of the rf voltage and the $\mathrm{rf}$ phase. An rf pulse power around $830 \mathrm{~kW}$ is needed for ${ }^{12} \mathrm{C}^{4+}$ operation.

The final beam emittances measured as $0.7 \mu \mathrm{m}$ (norm.) agree well with the design values [4]. $\mathrm{C}^{4+}$ currents of 


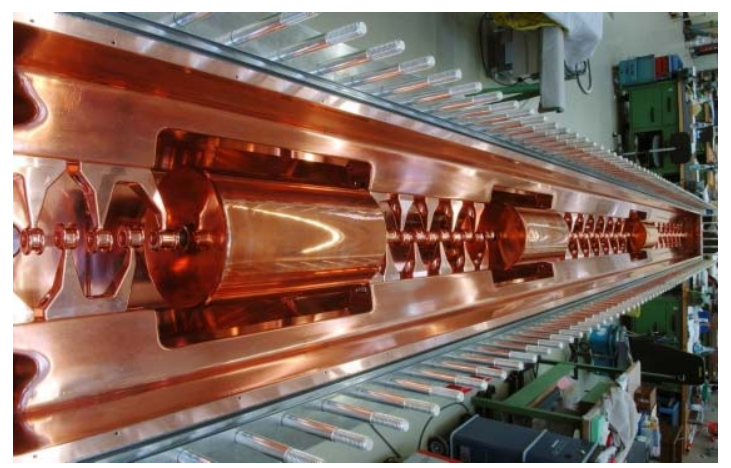

Figure 5: Open IH cavity after copper plating and installation of the drift tubes; the beam enters from the left.

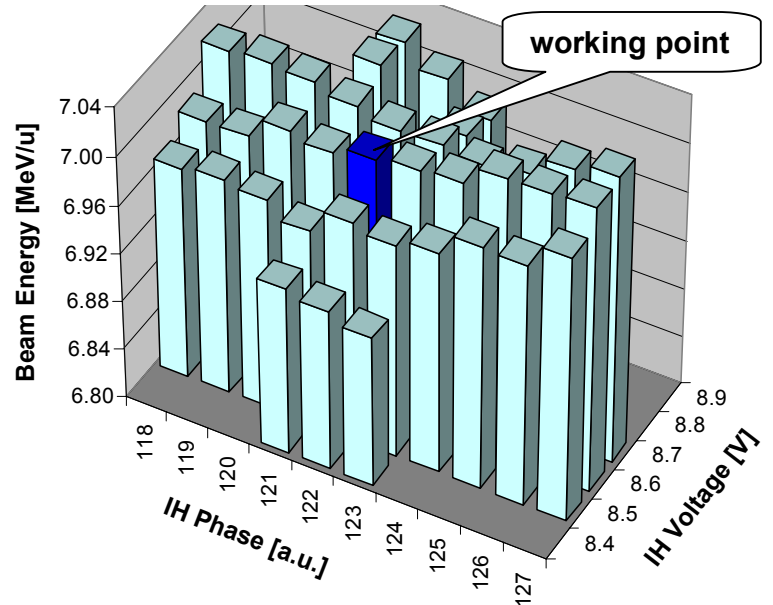

Figure 6: Final beam energy behind the linac as function of the (scaled) IH tank voltage and its rf phase (for ${ }^{12} \mathrm{C}^{4+}$ ).

35 to $40 \mathrm{e} \mu \mathrm{A}$ are achieved routinely in front of the foil stripper, resulting in $\mathrm{C}^{6+}$ currents of about $50 \mathrm{e} \mu \mathrm{A}$ at synchrotron injection.

\section{CONCLUSIONS AND OUTLOOK}

Finally, the linac could be commissioned successfully with carbon and hydrogen ion beams. Parameter sets for routine operation of the linac were defined. These include design optics for setting up the beam focusing as shown in Fig. 7. Beam commissioning of the synchrotron and later on of the treatment systems started in February 2007 using $\mathrm{C}^{6+}$ as well as proton beams. First $\mathrm{C}^{6+}$ beam was delivered to the treatment caves in March 2007. Start of patient irradiation is envisaged for winter 2007/2008.

The ion beam intensities are currently limited by the performance of the linac front-end system (ECRIS, final solenoid, RFQ): Low brilliances of the ECRIS beams accompanied by strong aberration effects of the solenoid focusing into the RFQ are causing significant mismatch to the RFQ acceptance. The misalignment of the RFQ structure results in a reduction of the RFQ acceptance. Finally, the beam divergence behind the RFQ is much larger as expected, causing strong beam losses in the subsequent doublet.

To enhance the performance of the linac front-end and to reach the design intensities an upgrade program has been defined. The solenoid magnet in front of the RFQ
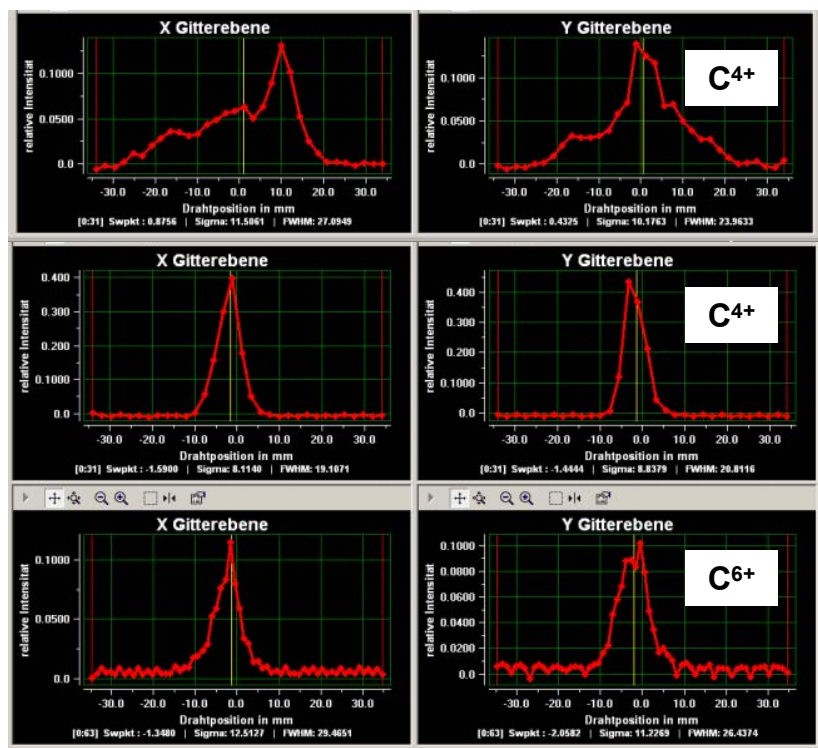

Figure 7: Horizontal (left) and vertical (right) LEBT beam profiles (top), behind the IH-DTL, and before synchrotron injection.

will be replaced in a shutdown period in summer 2007. A new design of the RFQ electrodes with an improved radial input matcher is in progress. It is also intended to reduce the strong beam divergence at the RFQ exit. A new RFQ tank has been built with larger wall thickness and an improved suspension in order to increase the rigidity of the RFQ and to reduce the misalignment and deformation of the RFQ structure. The new RFQ should be available for installation in Heidelberg in 2008.

The authors would like to thank many co-workers from the GSI accelerator division and from HIT for their fruitful cooperation and support during beam commissioning.

\section{REFERENCES}

[1] H. Eickhoff et al., HICAT - The German HospitalBased Light Ion Cancer Therapy Project, Proc. EPAC 2004, p. 290.

[2] B. Schlitt et al., Status of the $7 \mathrm{MeV} / \mathrm{u}, 217 \mathrm{MHz}$ Injector Linac for the Heidelberg Cancer Therapy Facility, Proc. LINAC 2004, p. 51.

[3] A. Bechtold et al., Status of the Integrated RFQDrifttube-Combination for the Medicine-Synchrotron in Heidelberg, Proc. PAC 2003, p. 1062.

[4] Y. Lu et al., The Compact 20 MV IH-DTL for the Heidelberg Therapy Facility, LINAC 2004, p. 57.

[5] B. Schlitt et al, Commissioning of the $7 \mathrm{MeV} / \mathrm{u}$, $217 \mathrm{MHz}$ Injector Linac for the Heavy Ion Cancer Therapy Facility at the University Clinics in Heidelberg, Proc. LINAC 2006, p. 148.

[6] C. Kleffner et al., Testbench of the HIT RFQ at GSI, Proc. LINAC 2006, p. 791.

[7] U. Ratzinger et al., NIM A 415, (1998).

[8] G. Clemente, H. Vormann et al., Assembly and RF Tuning of the IH-DTL for the HIT Linac, GSI Scientific Report 2006, p. 376. 